\title{
Characteristics of the Family Caregivers Who Did Not Benefit From a Successful Psychoeducational Group Intervention During Palliative Cancer Care A Prospective Correlational Study
}

Maja Holm, Kristofer Årestedt, Ida Carlander, Yvonne Wengström, Joakim Ohlen and Anette Alvariza

\section{Journal Article}

\section{Tweet}

N.B.: When citing this work, cite the original article.

Original Publication:

Maja Holm, Kristofer Årestedt, Ida Carlander, Yvonne Wengström, Joakim Ohlen and Anette Alvariza, Characteristics of the Family Caregivers Who Did Not Benefit From a Successful Psychoeducational Group Intervention During Palliative Cancer Care A Prospective Correlational Study, CANCER NURSING, 2017. 40(1), pp.76-83.

http://dx.doi.org/10.1097/NCC.0000000000000351

Copyright: Lippincott, Williams \& Wilkins http://www.lww.com/

Postprint available at: Linköping University Electronic Press

http://urn.kb.se/resolve?urn=urn:nbn:se:liu:diva-134068 


\section{Characteristics of family caregivers who did not benefit from a}

\section{successful psycho-educational group intervention during}

\section{palliative cancer care: a prospective correlational study}

Maja Holm, RN, MSc; Kristofer Årestedt, RN, PhD; Ida Carlander, RN, PhD; Yvonne Wengström, OCN, PhD; Joakim Öhlen RN, PhD; and Anette Henriksson, CNS, PhD

\section{Author Affiliations}

Department of Neurobiology, Care Science and Society, Karolinska Institutet, Stockholm, Sweden (Miss Holm and Drs Wengström and Henriksson); Palliative Research Centre, Ersta Sköndal University College, Stockholm, Sweden (Miss Holm and Drs Carlander, Öhlen and Henriksson); Department of Medical Health Sciences, Linköping University, Linköping, Sweden (Dr Årestedt); Centre for Collaborative Palliative Care, Linnaeus University, Kalmar, Sweden (Dr Årestedt); Department of Learning, Informatics, Management and Ethics. Karolinska Institutet, Stockholm, Sweden (Dr Carlander); School of Health and Medical Sciences, Örebro University, Örebro, Sweden (Dr Wengström); Institute of Health and Care Sciences, University of Gothenburg, Gothenburg, Sweden (Dr Öhlen); Department of Health Care Sciences, Ersta Sköndal University College, Stockholm, Sweden (Dr Henriksson) and Capio Palliative Care Unit, Dalen Hospital, Stockholm, Sweden (Dr Henriksson).

\section{Conflict of interest}

The authors have no conflicts of interest to disclose 


\section{Acknowledgments}

This work was supported by the Erling-Persson family foundation and the Swedish Cancer Society.

\section{Abstract}

Background: Although there has been a steady increase in intervention studies aimed towards supporting family caregivers in palliative cancer care, they often report modest effect sizes and there is a lack of knowledge about possible barriers to intervention effectiveness. Objective: To explore the characteristics of family caregivers who did not benefit from a successful psycho-educational group intervention compared to those who did.

Intervention/Methods: A psycho-educational intervention for family caregivers was delivered at 10 palliative settings in Sweden. Questionnaires were used to collect data at baseline and following the intervention. The preparedness for caregiving scale (PCS) was the main outcome for the study and was used to decide whether or not the family caregiver had benefited from the intervention (PCS difference score $\leq 0 \mathrm{vs} \geq 1$ ).

Results: 82 family caregivers completed the intervention and follow up. Caregivers who did not benefit from the intervention had significantly higher ratings of their preparedness and competence for caregiving and their health at baseline compared to the group who benefited. They also experienced lower levels of environmental burden and a trend towards fewer symptoms of depression.

Conclusions: Family caregivers who did not benefit from the intervention tended to be less vulnerable at baseline. Hence, the potential to improve their ratings was smaller than for the group who did benefit. 
Implications for practice: Determining family caregivers in cancer and palliative care who are more likely to benefit from an intervention needs to be explored further in research. 


\section{Background}

There has been an increasing focus on interventions directed at family caregivers in palliative cancer care as they often assume the role as primary caregiver and have the need for both information and practical support. ${ }^{1,2}$ A growing number of intervention studies aiming to improve family caregiver outcomes in cancer and palliative care have been identified ${ }^{3}$ and there has not only been an increase in quantity, but also in quality, with more studies identified with a higher grade of evidence. ${ }^{4}$

However, research regarding the most effective ways to provide support for family caregivers is still in its infancy. ${ }^{4}$ Interventions directed at family caregivers in cancer and palliative care have typically demonstrated modest effects while sample sizes have been small with high levels of attrition and thus the generalizability of the results has been limited. ${ }^{5-7}$ There is also a lack of consensus regarding which outcome measures should be applied ${ }^{3}$ as well as a lack of rigorous interventions based in theoretical and conceptual work. ${ }^{5}$ A randomized psychoeducational group intervention in palliative home care based on the theories of Andershed and Ternestedt ${ }^{8}$ had significant positive effects on family caregivers' feelings of preparedness for caregiving. ${ }^{9}$ Preparedness for caregiving has been defined as the perceived readiness to provide emotional and practical support and to manage the stressors of caregiving. ${ }^{10}$ Preparedness is associated with higher self-perceived health and rewards of caregiving and less anxiety, ${ }^{11}$ burden and depression. ${ }^{12}$ That intervention study had sufficient sample power and included validated statistical outcome measurements. ${ }^{9}$ However, the effect sizes on preparedness were also quite modest, indicating that all participants might not have benefited from the intervention. Increasing knowledge about barriers to intervention effectiveness could be an important factor in the development of new tailored interventions in palliative cancer care.$^{13}$ Hence, there is a need to focus on caregivers who benefit from an 
intervention and on those who do not. Therefore, the aim of this study was to explore the characteristics of family caregivers who did not improve their preparedness for caregiving by participating in a psycho-educational intervention in palliative cancer care compared to those who did.

\section{Method}

Design and setting

This study used a prospective correlational design and data from a previously conducted psycho-educational intervention study. The intervention was delivered at 10 different specialized palliative home care settings in a regional metropolitan area in Sweden which had between 70 and 200 patients enrolled. A majority of the patients were in different stages of an advanced cancer trajectory and were cared for in their own homes with health professionals making regular visits. Patients often had various and complex needs, including advanced symptom management, palliative oncological treatments and existential and practical support. The study settings mainly enrolled patients with various cancer diagnoses, but also patients with coronary and pulmonary diseases. Health professionals at the settings included physicians, nurses, social workers, priests and occupational and physical therapists.

The intervention was delivered as a randomized controlled trial with two arms at each of the 10 settings where family caregivers within each setting were randomized either to the intervention or to a control arm with standard support. The trial took place over fifteen months in 2013 and 2014. Each of the 10 settings participating in the trial delivered the intervention between 1-4 times and in total, 21 intervention programs were held. On average, 4 family caregivers participated in the intervention sessions. Questionnaires encompassing socio-demographic questions and statistical instruments were used to collect data at baseline 
and upon completion of the intervention. Ethical approval was granted by the regional ethical review board.

Intervention description

The intervention has been thoroughly described previously ${ }^{14}$ and has a psycho-educational design, including both supportive and educative components; the primary aim is to improve preparedness for caregiving. The intervention was developed based on the theoretical framework of Andershed and Ternestedt ${ }^{8}$ that conceptualizes the involvement and principal needs of family caregivers in palliative care to be knowing, being and doing. Knowing represents the family caregiver's need for information about things such as the patient's condition, symptoms and prognosis. Knowing could also be viewed as a prerequisite for being and doing. Being concerns the family caregiver's emotional needs; how to manage his or her own feelings as well as the patient's feelings. Doing has a practical dimension and involves the things the family caregiver needs to do for the patient, such as helping with medications and practical nursing care. The intervention is delivered as a program in group format by health professionals (nurse, physician and social worker/priest) at the palliative care setting where the patient is enrolled. The program entails three sessions which are planned to last two hours. Each session starts with coffee/tea and snacks being served, followed by a presentation of topics from an intervention manual by health professionals. The manual has been jointly developed by health professionals and researchers and consists of a compendium of evidence-based knowledge including topics focusing on the informational (knowing), emotional (being) and practical (doing) needs of family caregivers. Apart from the presentation, the sessions also include discussions and reflections about the topics between the family caregivers and health professionals and a short relaxing exercise. The intervention has an approach that is based on information and education (knowing). Through increased 
knowing family caregivers could become better prepared to manage practical caregiving (doing) and their own emotions as well as the patient's emotions in the situation (being). Throughout the intervention delivery, a nurse acts as group leader (Table 1).

Sample and procedure

Inclusion criteria for family caregivers were: being a family caregiver to a person in specialized palliative home care, over the age of 18 and able to understand Swedish. Patients and family caregivers were approached by health professionals at the settings with an invitation to the study. The patient was asked to give his/her permission to include the family caregiver(s) in the study and consent to some information being collected from patient records. If this was granted, the family caregiver was invited and asked to complete a baseline questionnaire. In total, 270 family caregivers accepted to participate. Each questionnaire had an ID number linked to the patient and was used to randomize family caregivers to one of the two arms; intervention or control. If the patient had more than one family caregiver who wished to participate, they were given questionnaires with the same ID number, to ensure allocation to the same arm. The allocation of family caregivers was made with the use of a random number sequence which had been generated through a computer program with the help of an independent statistician and stratified for each of the 10 palliative care settings. The number sequence included randomized permuted blocks of four.

148 family caregivers were randomised to the intervention arm and 122 to the control arm. No significant differences were found between these two groups at baseline. Because focus was on the characteristics of family caregivers who participated in the intervention, the control arm was excluded from this study. In total 89 family caregivers completed their participation in the intervention and measurements at baseline and upon completion. Because 
the primary outcome was related to preparedness for ongoing caregiving, caregivers of patients who had died before the follow-up had to be excluded, leaving 82 family caregivers as the final sample for this study (Figure). Even though the trial design allowed family caregivers of the same patient to participate, it was decided not to use nested data for the analysis because very few patients were represented by more than one family caregiver $(n=6)$ and hence it was considered that this would not influence the results.

The questionnaires

The questionnaires included socio-demographic questions and self-reported instruments. The variables for this study were chosen on the basis of being considered important for whether or not the family caregiver had benefited from the intervention. The socio-demographic questions included the caregiver's age, sex, marital and financial status, education, occupation, morbidity and relation to the patient. Data were also gathered from patient records regarding patient diagnosis, years since diagnosis and time in palliative care.

The Preparedness for Caregiving Scale (PCS) was the primary outcome for the intervention. It measures perceived readiness for various domains of caregiving ${ }^{10,15,16}$ on a five-point Likert-type scale ranging from 'not at all prepared' (0) to 'very well prepared' (4) with a total score ranging from 0-32.

The Caregiver Competence Scale (CCS) measures competence/knowledge for caregiving. ${ }^{15,17}$ It consists of four items on a four-point Likert-type scale ranging from 'not at all competent' (0) to 'very competent' (3) with a total score ranging from 0-12. 
A modified version of the Rewards for Caregiving Scale (RCS) was used to measure personal rewards for caregiving. ${ }^{15,18}$ It consists of 10 items on a five-point Likert-type scale. The score ranges from 'not rewarding at all' (0) to 'very rewarding' (4) with a total score ranging from $0-40$.

The Caregiver Burden Scale (CBS) measures burden in caregiving. ${ }^{19}$ It consists of five subscales; general strain, isolation, disappointment, emotional involvement and environment. The 22 items are answered on a four-point Likert-type scale, ranging from 'not at all' (1) to ‘often’ (4) where higher scores indicate greater caregiver burden. The item scores of each dimension are summed and a mean value for each dimension is calculated with scores ranging from 1-4.

The Health Index (HI) was used to measure self-perceived health. ${ }^{20}$ It consists of 11 items answered on a four-point Likert-type scale ranging from 1-4 with a higher value indicating better health. The total score ranges from 11-44. For this study, HI was measured both as a total score but also with two single items asking about family caregivers' health in the last week and their overall health.

The Hospital Anxiety and Depression Scale (HADS) was used to measure anxiety and symptoms of depression in family caregivers through two subscales. ${ }^{21,22}$ The seven items of each subscale are answered on a four-point Likert-type scale ranging from 0-3 with a higher value indicating higher levels of anxiety/depression respectively. For each subscale, the total score ranges from $0-21$. 
The Multiple Scale of Perceived Social Support (MSPSS) measures social support. ${ }^{23}$ It consists of 12 items ranging from 1-7 where higher values indicate a higher perceived social support. It includes three subscales: family, friends and significant others. The subscales have a total score of between 4 and 28 each.

Analysis

Analysis for this study was undertaken by using data from the intervention group. To identify family caregivers who did and did not increase their preparedness for caregiving by participating in the intervention, difference scores of the PCS were calculated between baseline and follow-up. If the difference was 0 or below, the family caregivers were considered not to have benefited from the intervention. If the difference was 1 or above, they were considered to have benefited from the intervention. These two groups are hereafter referred to as the non-benefit group and the benefit group.

Different statistical methods were used, depending on the level and distribution of data. The characteristics between the non-benefit and benefit groups were compared using baseline data. Chi-squared tests were used for categorical socio-demographic variables (sex, marital status, education, occupation, and illness) and unpaired $t$-tests for continuous variables (age, years since patient diagnosis). If the expected values of contingency cells were below 5, the Fisher's exact test was applied for categorical variables (relation to patient, financial status, patient diagnosis and time in palliative care). For continuous self-reported instruments, the non-parametric Mann-Whitney U-test was used (PCS, CCS, RCS, CBS, HI, HADS, MSPSS) as most of them were skewed and it could be argued that they could be classified as either numerical or ordinal data. The statistical significance level was set at $p<.05$, while $p<.1$ was 
set as a considerable trend towards significance. All statistical analyses were carried out using the STATA version 13.1 for Windows (Stata Corp LP, College Station TX, USA).

\section{Results}

Sample characteristics

Of the 82 family caregivers included in this study, 26 (32\%) were men and 56 (68\%) were women. They had a mean age of 62 years and $90 \%$ cared for a patient with a cancer diagnosis. A majority of the family caregivers were spouses or partners (59\%) of the patient and lived in the same home (64\%) (Table 2). Calculations of differences between baseline and follow-up measurements revealed that 45 (55\%) had improved their ratings in the PCS by participating in the intervention (benefit group), while 37 (45\%) had not (non-benefit group).

Differences in characteristics between benefit and non-benefit group No significant differences were found in socio-demographic variables such as the family caregiver's age, sex, marital and financial status, education, morbidity and relation to the patient between the benefit and non-benefit groups, or in variables such as the patient's diagnosis or amount of time in palliative care. However, there was a considerable trend towards significance, indicating that family caregivers who did not work (retired, unemployed, on sick-leave) were more likely not to benefit from the intervention compared to those who were working or studying ( $p=.058$ ) (Table 3).

At baseline, family caregivers in the non-benefit group had significantly higher levels in the PCS ( $p<.001)$ and CCS ( $p=.003)$ compared to the benefit group. They had also significantly higher levels in the HI scale, both in the total score $(p=.039)$ and in the single item about overall health $(p=.030)$. They had significantly lower ratings of their CBS-environment 
( $p=.048$ ) while a considerable trend towards significance was found for lower ratings in the HADS-symptoms of depression $(p=.098)$. We found no differences between the groups with regards to their rating of the RCS, the remaining CBS subscales, HADS-anxiety, HI-last week or any of the MSPSS subscales (Table 4).

\section{Discussion}

This is, to the authors' knowledge, the first study investigating the characteristics of family caregivers who did not benefit from a psycho-educational intervention during palliative cancer care compared to those who did by looking at the differences in their baseline ratings.

The major finding of this study was that family caregivers who did not benefit from the intervention generally scored "better" in the self-rated instruments at baseline. In several of the scores, there were either significant differences or a considerable trend towards significance between the groups with the non-benefit group scoring "better” in instruments measuring things such as preparedness, competence, health, environmental burden and symptoms of depression. These results could indicate that because the non-benefit group was less vulnerable at baseline it might have been difficult to improve their scores compared to the benefit group. It has also been found that the PCS may not have the ability to capture changes in family caregivers with very high or very low scores. ${ }^{16}$ Previous research has found that well-adapted family caregivers are more likely to be included in research studies in cancer and palliative care, which could affect the outcome of interventions and reduce potential effects. ${ }^{5,24}$ Therefore, a way to enhance effect sizes could be to focus interventions on more vulnerable family caregivers. ${ }^{25,26}$ 
Screening instruments have been developed to identify the supportive and educative needs of family caregivers in cancer and palliative care 27,28 and these could be used to target family caregivers in special need of an intervention. The primary outcome for this intervention was preparedness for caregiving and the PCS could also be used as a possible screening instrument. Preparedness for caregiving has been suggested as something that could moderate negative aspects of family caregiving and promote supportive factors. ${ }^{11,12}$ Hence, it could be important to identify low-scorers of the instrument who might benefit from an intervention aiming to promote preparedness for caregiving. Because resources in clinical practice are often limited, it has also been suggested that the health professional support mainly should target family caregivers who are in most need of it. ${ }^{29}$

However, it is difficult to recommend screening based only on these results, because it is unknown how the preparedness for caregiving in the non-benefit group would have developed if they had not taken part in the intervention. Preparedness for caregiving has previously been described as an ongoing movement with fluctuating needs, ${ }^{30}$ indicating that it should be measured continuously. It is also possible that the non-benefit-group would have benefited more from other kinds of support or could have benefited from the intervention in other ways than how was measured in this study. Qualitative studies of group interventions in cancer and palliative care have shown that one of the main rewards was meeting other family caregivers and creating a basis for future networking ${ }^{14,31,32}$, something that was not studied in this paper.

It is noteworthy that no significant differences in socio-demographic characteristics of family caregivers were found between the non-benefit group and the benefit group. It could be considered a strength of this intervention that its potential benefits to family caregivers were 
not depending on variables such as their age or sex which has previously been found influential to intervention results. ${ }^{25}$ Earlier research has indicated that the wellbeing of family caregivers are influenced by a diversity of variables such as their relationship to the patient ${ }^{33}$ and the patient's condition, ${ }^{34}$ however, in this study it could not be pinpointed that these variables influenced the results of the intervention on their own.

\section{Limitations}

This study has several limitations which should be considered in relation to the results presented. The sample was limited and power analysis was not calculated as only family caregivers who had completed the intervention and the questionnaires were included. Because this could increase the risk of Type II errors, the decision was made to describe the variables that showed trends towards significance $(p<.1)$. However, these results should be interpreted with caution. Another limitation of the study is that there is no data on family caregivers who refused to participate in the intervention study. It would have been valuable to investigate the characteristics of this group in comparison to the two groups in the study especially with regards to perceived vulnerability. The division between the non-benefit and benefit group (PCS difference score $\leq 0 \mathrm{vs} \geq 1$ ) represents another potential weakness of the study. This difference was not based on stated guidelines, because it could not be found in the literature. Therefore, the use of this measurement should be considered tentatively.

\section{Conclusion}

It is difficult to draw conclusions from this prospective-correlational study of a psychoeducational intervention aiming to promote preparedness for caregiving during palliative home care. Many different variables probably work together to influence family caregivers' benefit or non-benefit of an intervention. However, the results indicate that family caregivers 
who did not benefit from the intervention were less vulnerable than the benefit group at baseline and that they might have been in less need of the intervention. Intervention trials in palliative and cancer care often report modest effect sizes and this study could provide knowledge about the sampling of family caregivers in order to promote greater effects. However, it is still possible that the non-benefit group benefited from the intervention in other ways than how it was measured.

Clinical and research implications

The results of this study provide insights that point towards a possible need for health professionals to target and invite vulnerable family caregivers in palliative cancer care to psycho-educational interventions because they might benefit more from them. Considering the often limited resources in clinical practice, it could be reasonable to focus interventions on family caregivers who would be expected to need them most. However, it is still necessary to develop further knowledge before stating such clinical implications. To capture an overreaching image of family caregivers who do and do not benefit from an intervention in palliative cancer care, it might be necessary to adapt multi-faceted research strategies, including qualitative and quantitative methods.

The trial has been registered at www.clinicaltrials.gov; ID: NCT02482415. 


\section{References}

1. Stajduhar KC, R. . Family caregiving in the home. Family carers in palliative care - a guide for health and social care profesionals Oxford: Oxford University Press; 2009:149-168.

2. Bee PE, Barnes P, Luker KA. A systematic review of informal caregivers' needs in providing home-based end-of-life care to people with cancer. Journal of clinical nursing. 2009;18(10):1379-1393.

3. Harding R, List S, Epiphaniou E, Jones H. How can informal caregivers in cancer and palliative care be supported? An updated systematic literature review of interventions and their effectiveness. Palliative medicine. 2012;26(1):7-22.

4. Hudson PL, Remedios C, Thomas K. A systematic review of psychosocial interventions for family carers of palliative care patients. BMC palliative care. 2010;9:17.

5. Candy B, Jones L, Drake R, Leurent B, King M. Interventions for supporting informal caregivers of patients in the terminal phase of a disease. The Cochrane database of systematic reviews. 2011(6):CD007617.

6. Harding R. Caregivers of people at the end of life: emerging evidence. Current opinion in supportive and palliative care. 2014;8(4):391-393.

7. Preston NJ, Fayers P, Walters SJ, et al. Recommendations for managing missing data, attrition and response shift in palliative and end-of-life care research: part of the MORECare research method guidance on statistical issues. Palliative medicine. 2013;27(10):899-907.

8. Andershed B, Ternestedt BM. Development of a theoretical framework describing relatives' involvement in palliative care. Journal of advanced nursing. 2001;34(4):554-562.

9. Holm M, Årestedt, K, Carlander, I, Fürst, CJ, Wengström, Y, Öhlen, J \& Henriksson, A. Short and long-term effects of a psycho-educational group intervention for family caregivers in palliative home care - results from a randomised control trial In press2015.

10. Archbold PG, Stewart BJ, Greenlick MR, Harvath T. Mutuality and preparedness as predictors of caregiver role strain. Research in nursing \& health. 1990;13(6):375-384.

11. Henriksson A, Arestedt K. Exploring factors and caregiver outcomes associated with feelings of preparedness for caregiving in family caregivers in palliative care: A correlational, cross-sectional study. Palliative medicine. 2013;27(7):639-646.

12. Schumacher KL, Stewart BJ, Archbold PG. Mutuality and preparedness moderate the effects of caregiving demand on cancer family caregiver outcomes. Nursing research. 2007;56(6):425-433.

13. Grande G, Stajduhar K, Aoun S, et al. Supporting lay carers in end of life care: current gaps and future priorities. Palliative medicine. 2009;23(4):339-344.

14. Holm M, Carlander I, Furst CJ, et al. Delivering and participating in a psycho-educational intervention for family caregivers during palliative home care: a qualitative study from the perspectives of health professionals and family caregivers. BMC palliative care. 2015;14:16.

15. Henriksson A, Andershed B, Benzein E, Arestedt K. Adaptation and psychometric evaluation of the Preparedness for Caregiving Scale, Caregiver Competence Scale and Rewards of Caregiving Scale in a sample of Swedish family members of patients with lifethreatening illness. Palliative medicine. 2012;26(7):930-938.

16. Henriksson A, Hudson P, Ohlen J, et al. Use of the Preparedness for Caregiving Scale in Palliative Care: A Rasch Evaluation Study. Journal of pain and symptom management. 2015.

17. Pearlin LI, Mullan JT, Semple SJ, Skaff MM. Caregiving and the stress process: an overview of concepts and their measures. The Gerontologist. 1990;30(5):583-594.

18. Archbold PG, Stewart. B. Family caregiving inventory. Portland: Oregon Health Sciences University; 1996. 
19. Elmstahl S, Malmberg B, Annerstedt L. Caregiver's burden of patients 3 years after stroke assessed by a novel caregiver burden scale. Archives of physical medicine and rehabilitation. 1996;77(2):177-182.

20. Forsberg C, Bjorvell H. Swedish population norms for the GHRI, HI and STAI-state. Quality of life research: an international journal of quality of life aspects of treatment, care and rehabilitation. 1993;2(5):349-356.

21. Lisspers J, Nygren A, Soderman E. Hospital Anxiety and Depression Scale (HAD): some psychometric data for a Swedish sample. Acta psychiatrica Scandinavica. 1997;96(4):281-286.

22. Zigmond AS, Snaith RP. The hospital anxiety and depression scale. Acta psychiatrica Scandinavica. 1983;67(6):361-370.

23. Ekback M, Benzein E, Lindberg M, Arestedt K. The Swedish version of the multidimensional scale of perceived social support (MSPSS)--a psychometric evaluation study in women with hirsutism and nursing students. Health and quality of life outcomes. 2013;11:168.

24. Schildmann EH, I. Evaluating psycho-educational interventions for informal carers of patients receiving cancer care or palliative care: Strengths and limitations of different study designs. Palliative medicine. 2010;25(4):345-356.

25. Hudson P, Trauer T, Kelly B, et al. Reducing the psychological distress of family caregivers of home-based palliative care patients: short-term effects from a randomised controlled trial. Psycho-oncology. 2013;22(9):1987-1993.

26. McCorkle R, Pasacreta JV. Enhancing caregiver outcomes in palliative care. Cancer control : journal of the Moffitt Cancer Center. 2001;8(1):36-45.

27. Ewing G, Grande G, National Association for Hospice at H. Development of a Carer Support Needs Assessment Tool (CSNAT) for end-of-life care practice at home: a qualitative study. Palliative medicine. 2013;27(3):244-256.

28. Knighting K, O'Brien MR, Roe B, et al. Development of the Carers' Alert Thermometer (CAT) to identify family carers struggling with caring for someone dying at home: a mixed method consensus study. BMC palliative care. 2015;14:22.

29. Hudson P, Payne S. Family caregivers and palliative care: current status and agenda for the future. Journal of palliative medicine. 2011;14(7):864-869.

30. Holm M, Henriksson A, Carlander I, Wengstrom Y, Ohlen J. Preparing for family caregiving in specialized palliative home care: An ongoing process. Palliative \& supportive care. 2015;13(3):767-775.

31. Henriksson A, Andershed B. A support group programme for relatives during the late palliative phase. International journal of palliative nursing. 2007;13(4):175-183.

32. Milberg A, Rydstrand K, Helander L, Friedrichsen M. Participants' experiences of a support group intervention for family members during ongoing palliative home care. Journal of palliative care. 2005;21(4):277-284.

33. Hauser JM, Kramer BJ. Family caregivers in palliative care. Clinics in geriatric medicine. 2004;20(4):671-688, vi.

34. Stromberg A, Luttik ML. Burden of caring: risks and consequences imposed on caregivers of those living and dying with advanced heart failure. Current opinion in supportive and palliative care. 2015;9(1):26-30. 
Table 1: The data collection and intervention process

Table 2: Family caregiver characteristics at baseline

Table 3: Differences in socio-demographic variables between non benefit/benefit group

Table 4: Differences in self-reported instruments at baseline between non benefit/ benefit group

Figure: Inclusion in the study 


\section{Table 1. The Data Collection and Intervention Process}

\section{Baseline Questionnaire - Before Intervention Start}

\begin{tabular}{|c|c|c|c|c|}
\hline \multirow{3}{*}{$\begin{array}{l}\text { Time Frame } \\
\text { of The } \\
\text { Intervention }\end{array}$} & $\begin{array}{l}\text { Session } \\
\text { Number }\end{array}$ & $\begin{array}{l}\text { Health } \\
\text { Professionals }\end{array}$ & Main Topic & Examples of Content \\
\hline & Session 1 & $\begin{array}{l}\text { Group leader } \\
\text { (nurse) }+ \\
\text { physician }\end{array}$ & $\begin{array}{l}\text { Palliative care and } \\
\text { symptom } \\
\text { management. }\end{array}$ & $\begin{array}{l}\text { - } \quad \text { Palliative care philosophy } \\
\text { - Common patient symptoms such as pain, } \\
\text { nausea and anxiety and their management } \\
\text { - The very last phase of life, how the body } \\
\text { changes and the process of preparing for death }\end{array}$ \\
\hline & Session 2 & $\begin{array}{l}\text { Group leader } \\
\text { (nurse) }\end{array}$ & $\begin{array}{l}\text { Daily life and } \\
\text { practical nursing } \\
\text { care }\end{array}$ & $\begin{array}{l}\text { - Being a family caregiver; changing roles and } \\
\text { relations } \\
\text { - Nutritional problems such as lack of appetite, } \\
\text { constipation and xerostomia; explanations and } \\
\text { management } \\
\text { - Helping with personal and intimate care; how } \\
\text { to manage practical and emotional aspects }\end{array}$ \\
\hline 3 weeks & Session 3 & $\begin{array}{l}\text { Group leader } \\
\text { (nurse) + social } \\
\text { worker or priest }\end{array}$ & $\begin{array}{l}\text { Emotional } \\
\text { reactions and grief }\end{array}$ & $\begin{array}{l}\text { - } \text { Grief reactions and the individual variations } \\
\text { - } \quad \text { Coping, hope and resilience } \\
\text { - Perspectives on death and dying in the modern } \\
\text { - } \text { developed world } \\
\text { - Support systems in society }\end{array}$ \\
\hline
\end{tabular}

Follow-Up Questionnaire - Upon Completion of The Intervention 
Table 2. Family Caregiver Characteristics at Baseline

\section{Characteristics}

Caregiver age Mean (SD)

Sex n (\%)

Male

Female

Education n (\%)

University degree

Below university

Marital status n (\%)

Married/cohabiting

Unmarried

Relation to patient n (\%)

Spouse/partner

Parent

Other

Living with patient $\mathrm{n}(\%)$

Yes

No

Occupation n (\%)

Working/studying

Not working/retired

Financial situation $\mathrm{n}(\%)$

Good/very good

Bad/very bad

Presence of mental/physical illness in caregiver n (\%)

Yes

No
Family Caregivers

$(\mathbf{n}=\mathbf{8 2})$

62.2 (12.9)

$26(32)$

$56(68)$

35 (43)

46 (57)

65 (79)

17 (21)

48 (59)

24 (29)

$10(12)$

$52(63)$

30 (37)

36 (44)

46 (56)

72 (89)

9 (11)

45 (55)

37 (45) 
Patient diagnosis n (\%)

Cancer diagnosis

$74(90)$

Other diagnosis

Instrument ratings Mean (SD)

Preparedness for caregiving

Competence for caregiving

$17.05(6.77)$

Rewards for caregiving

$6.41(2.85)$

Caregiver Burden -general strain

$27.58(8.20)$

$2.35(0.70)$

$2.12(0.68)$

$2.43(0.90)$

Caregiver Burden-isolation

$1.85(0.69)$

Caregiver Burden-emotional involvement

$1.99(0.72)$

$34.29(5.28)$

Health Index - total score

$3.29(0.58)$

$3.23(0.67)$

$7.85(4.44)$

$5.19(3.53)$

Anxiety

$22.10(5.93)$

Social support - family

Social support - friends

$20.99(6.01)$

Social support - significant others

22.48 (6.11)

Abbreviations: SD, standard deviation 
Table 3. Differences in Socio-Demographic Variables Between Non-benefit/Benefit Group

\begin{tabular}{|c|c|c|c|}
\hline Socio-demographic Variables & $\begin{array}{l}\text { Non-benefit } \\
(n=37)\end{array}$ & $\begin{array}{l}\text { Benefit } \\
(n=45)\end{array}$ & $P$-value \\
\hline Caregiver age Mean (SD) & $64.76(10.63)$ & $60.10(14.25)$ & $.1014^{\mathrm{a}}$ \\
\hline \multicolumn{3}{|l|}{ Sex n (\%) } & \multirow[t]{3}{*}{$.545^{\mathrm{b}}$} \\
\hline Male & $13(35)$ & $13(29)$ & \\
\hline Female & $24(65)$ & $32(71)$ & \\
\hline \multicolumn{3}{|l|}{ Education n (\%) } & \multirow[t]{3}{*}{$.913^{\mathrm{b}}$} \\
\hline University degree & $16(43)$ & $20(44)$ & \\
\hline Below university & $21(57)$ & $25(56)$ & \\
\hline \multicolumn{3}{|l|}{ Marital status n (\%) } & \multirow[t]{3}{*}{$.360^{\mathrm{b}}$} \\
\hline Married/cohabiting & $31(84)$ & $34(76)$ & \\
\hline Unmarried & $6(16)$ & $11(24)$ & \\
\hline \multicolumn{3}{|l|}{ Relation to patient n (\%) } & \multirow[t]{4}{*}{$1.000^{\mathrm{C}}$} \\
\hline Spouse/partner & 22 (59) & $26(58)$ & \\
\hline Parent & $11(30)$ & $13(29)$ & \\
\hline Other & $4(11)$ & $6(13)$ & \\
\hline \multicolumn{3}{|l|}{ Living with patient n (\%) } & \multirow[t]{3}{*}{$.831^{\mathrm{b}}$} \\
\hline Yes & $23(62)$ & $29(64)$ & \\
\hline No & $14(38)$ & $16(36)$ & \\
\hline \multicolumn{3}{|l|}{ Occupation n (\%) } & \multirow[t]{3}{*}{$.058^{\mathrm{b}}$} \\
\hline Working/studying & $12(32)$ & $24(53)$ & \\
\hline Not working/retired & $25(68)$ & $21(47)$ & \\
\hline \multicolumn{3}{|l|}{ Financial situation n (\%) } & \multirow[t]{3}{*}{$.724^{\mathrm{c}}$} \\
\hline Good/very good & $33(92)$ & $39(87)$ & \\
\hline Bad/very bad & $3(8)$ & $6(13)$ & \\
\hline \multicolumn{3}{|l|}{ Presence of mental/physical } & \multirow[t]{4}{*}{$.450^{\mathrm{b}}$} \\
\hline illness in caregiver $\mathrm{n}(\%)$ & $15(41)$ & $23(51)$ & \\
\hline Yes & $22(59)$ & $22(49)$ & \\
\hline No & & & \\
\hline
\end{tabular}


Patient diagnosis n (\%)

Cancer diagnosis

$31(84)$

Other diagnosis

$6(16)$

43 (96)

2 (4)

Patient time in palliative care $\mathrm{n}$

14 (38)

9 (24)

$12(32)$

2 (5)

$.132^{\mathrm{c}}$

(\%)

3-6 months

6 months-1 year

4 (4.55)

16 (35)

$13(29)$

8 (18)

8 (18)

Years since patient diagnosis

Mean (SD)

$5(5.64)$

$.230^{c}$

Abbreviations: SD, standard deviation

a: t-test

b: x2-test

c: Fisher's exact test 
Table 4. Differences in Self-Reported Instruments at Baseline Between Non-benefit/ Benefit Group

$\begin{array}{lllll}\text { Variable } & \text { Non-benefit Md q1-q3 } & \text { Benefit Md q1-q3 } & \text { Z-value } & \begin{array}{l}P \text {-value } \\ \text { Preparedness for caregiving }\end{array} \\ \text { Competence for caregiving } & 22(16-24) & 14(10-18) & 4.856 & <.001 \\ \text { Rewards for caregiving } & 8(6-9) & 6(4-8) & 2.950 & .003 \\ \text { Caregiver Burden - general strain } & 28(21-33) & 28.5(22-35.5) & -1.000 & .281 \\ \text { Caregiver Burden - disappointment } & 2.5(1.6-3.1) & 2.38(2-2.8) & 0.779 & .391 \\ \text { Caregiver Burden - isolation } & 2(1.4-2.6) & 2.2(1.8-2.6) & -0.362 & .758 \\ \text { Caregiver Burden - emotional involvement } & 2.33(1.7-3) & 2.67(1.7-3) & -0.243 & .903 \\ \text { Caregiver Burden - environment } & 1.67(1-2.7) & 1.67(1.3-2.3) & -0.034 & .959 \\ \text { Health Index - total score } & 1.67(1.3-2.3) & 2(1.7-2.7) & -1.930 & .048 \\ \text { Health Index - general } & 36(34-39) & 34(31-37) & 2.063 & .045 \\ \text { Health Index - last week } & 4(3-4) & 3(3-3) & 2.177 & .026 \\ \text { Anxiety } & 3(3-4) & 3(3-4) & 1.062 & .349 \\ \text { Depression } & 6(5-8.5) & 9(5-10) & -1.651 & .146 \\ \text { Social support - family } & 4(2-6.5) & 6(3-7) & -1.714 & .098 \\ \text { Social support - friends } & 25(20-28) & 23.5(19-26) & 1.175 & .190 \\ \text { Social support - significant others } & 23(18-26) & 21(16-25) & 0.643 & .432\end{array}$

Abbreviations: Md, median q1, quartile 1, q3, quartile 3 
Figure. Inclusion in the study

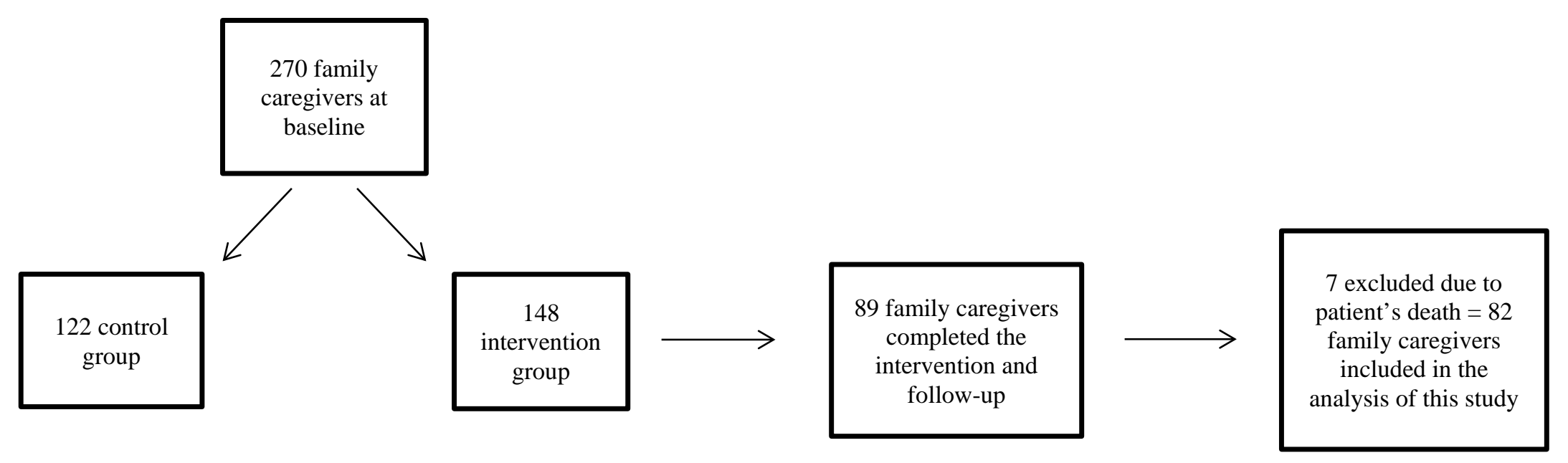

